\title{
Secondary Emissions from Catalytic Active Particle Filter Systems
}

A. Mayer, N. Heeb, J. Czerwinski and M. Wyser TTM, EMPA, AFHB, BUWAL

Reprinted From: Diesel Emission Measurement and Modeling (SP-1755 / SP-1754CD) 
All rights reserved. No part of this publication may be reproduced, stored in a retrieval system, or transmitted, in any form or by any means, electronic, mechanical, photocopying, recording, or otherwise, without the prior written permission of SAE.

For permission and licensing requests contact:
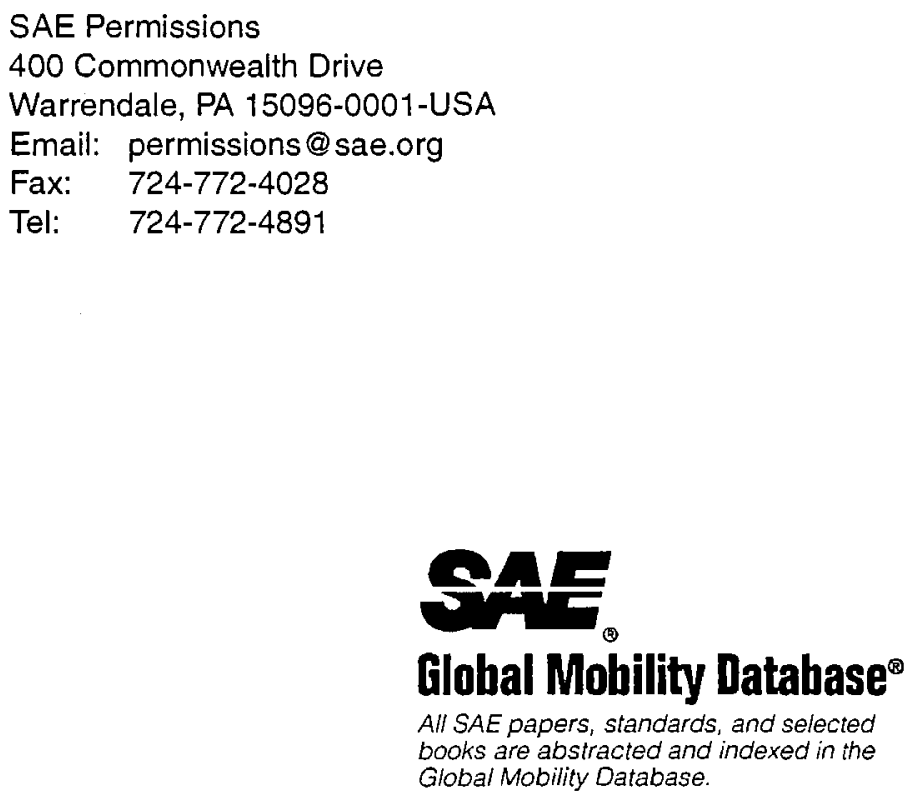

For multiple print copies contact:

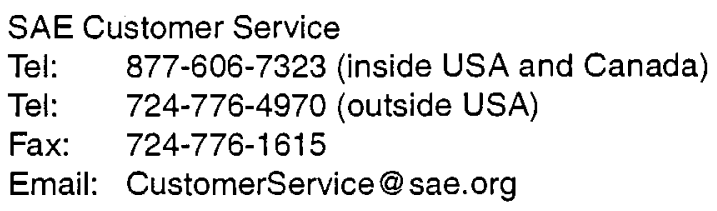

\section{ISSN 0148-7191}

\section{Copyright $\odot 2003$ SAE International}

Positions and opinions advanced in this paper are those of the author(s) and not necessarily those of SAE. The author is solely responsible for the content of the paper. A process is available by which discussions will be printed with the paper if it is published in SAE Transactions.

Persons wishing to submit papers to be considered for presentation or publication by SAE should send the manuscript or a 300 word abstract of a proposed manuscript to: Secretary, Engineering Meetings Board, SAE.

\section{Printed in USA}




\title{
Secondary Emissions from Catalytic Active Particle Filter Systems
}

\author{
A. Mayer, N. Heeb, J. Czerwinski and M. Wyser
}

TTM, EMPA, AFHB, BUWAL

Copyright $\odot 2003$ SAE International

\begin{abstract}
Fine pored hot gas traps have filtration efficiencies exceeding $99 \%$ of the solid particles in the diesel exhaust gas. There is a favorable trend to deploy this technology ex-factory and retrofitting on-road and offroad engines.
\end{abstract}

The trap system however functions as a chemical reactor. The filter has a large effective area and the engine exhaust gas has plenty of reactants, which can promote undesirable chemical reactions that release toxic secondary emissions. These effects may be amplified when traps have catalytic influence, e.g. due to surface coatings or fuel-borne catalysts.

The VERT suitability tests for particle trap systems therefore include a detailed test procedure for verifying the presence of over 200 toxic substances. These include PAH, nitro-PAH, chlorinated dioxins, furans as well as metals.

The paper describes test procedures, test reporting, sample extraction and analysis. Experimental results are obtained for three important topics: dioxins and furans do not form in most trap system. An exception is additives containing copper, which can cause four orders of magnitude jump in these highly toxic emissions. Trap technology curtails the less volatile but tends to increase the more volatile nitro-PAH. Traps coated with precious metals can cause massive increase in $\mathrm{NO}_{2}$ emissions and pronounced sulfating.

The results substantiate the necessity to certify particle trap systems after investigating any possible secondary emissions. This requirement is legislated in Switzerland.

\section{RESEARCH MOTIVATION}

The primary attribute of particle traps is the ability to filter more than $99 \%$ of the solid particles from the exhaust of internal combustion engines. Even under very difficult conditions, the filtered exhaust from a diesel engine has fewer particles than in the input air [1]. Because of their large specific surface $>100$ $\mathrm{m}^{2} / \mathrm{g}$ ), the soot particles are a carrier for several lowvolatile substances, e.g. polycyclic aromatic hydrocarbons (PAH), which are thus also filtered from the exhaust gases [2].

Trap systems can also be enhanced with catalytic functions that lower the soot light-off temperature. The high oxygen content of the diesel exhaust facilitates and accelerates further chemical reactions, e.g. oxidation of $\mathrm{CO}$ to $\mathrm{CO}_{2}$ and conversion of volatile hydrocarbons to harmless $\mathrm{CO}_{2}$ and $\mathrm{H}_{2} \mathrm{O}$. The gases flow through filter structures having fine porosity filter media that ensure a very good mass transfer. Such chemical reactions complete almost fully.

However, catalytic activity also has the inherent hazard of synthesizing toxic substances, which were either not previously present in the exhaust gas or at lower concentration levels. These so-called secondary emissions can result from the following reactions:

- $\quad \mathrm{NO}_{2}$ from $\mathrm{NO}$

- $\mathrm{SO}_{3}$ from $\mathrm{SO}_{2}$

- Formation of toxic hydrocarbons

- Formation of toxic aldehydes

- Modification of the PAH profile

- Formation of chlorinated dioxins and furans

- Nitration of PAH (nitro-PAH) 
As a rule, such reactions do not occur in the exhaust gas path of an engine without trap. The dwell time is only fractions of a second and insufficient for secondary emissions.

Traps, however, are a completely different situation that is best described as a chemical reactor. The surface of the filter can by soot deposition have an area of $1,000 \mathrm{~m}^{2} / \mathrm{kW}$. This large surface can adsorb substances that dwell there nearly indefinitely. The number of reactants, even when only in trace quantities, in exhaust gas can be thousands of chemical compounds. Besides nitrogen and oxygen, there are innumerable hydrocarbons, sulfur compounds and also small quantities of chlorine. The exhaust gas temperature is in the range from room temperature to $600^{\circ} \mathrm{C}$; conducive to many adsorption/ desorption patterns. Under these circumstances, none of the mentioned reactions can be excluded a priori.

Particle trap systems can form highly toxic substances, albeit only in trace quantities. It is an urgent necessity to verify the presence of such secondary emissions with the suitability tests.

\section{SWISS STIPULATIONS}

Traps must comply with the legislation of the Swiss environmental authorities [3] and the Swiss federal police and justice department [4]:

- Fuel-borne and substrate-bound catalyst supported regeneration methods are only permissible when the health and environmental impact of secondary reaction products can be excluded [4]. Compliance with this stipulation is focus of this paper.

- Size-specific metal analysis of treated exhaust gas shall verify penetration of metal particles through the trap. It is the topic of the parallel SAE paper [5].

- Further, each combination of filter and catalyst must successfully complete the filter test (VFT) The filtration rate for catalyst particles of all size categories must be equivalently effective as for soot particles. A bimodal size-distribution in the treated gas, indicating excessive concentration of catalyst particles in certain size categories, is not permissible.

- Fuel-borne catalysts must be registered as new substances and their toxicity classified.

- Automated dosage is mandatory for trap deployment. Also necessary is a safety concept that interrupts catalyst supply when trap failure is detected.

- Fuel-borne catalysts are only permitted for retrofit in Switzerland after testing in combination with a specific trap.
The verification of trap systems compliance with the above stipulations is done in the so-called VSET (VERT Secondary Emission Test). It is part of the VERT suitability test suite for particle trap systems.

The evaluation of the results is substance-specific and oriented towards the individual emission criteria in the deployed situation:

- The concentration of each pollutant in the exhaust gas shall not be relevantly higher than the reference value without trap.

- Pollutant restrictions for respiratory air may constrain deployment, i.e. further restrict the number of vehicles in the controlled space.

\section{VSET TEST METHODOLOGY}

The purpose of the VSET test is to identify traces of toxic emissions. Hence, the test cycle must fulfill three conditions:

- The test cycle must be representative of typical operational deployment.

- The test cycle must contain realistic worst case conditions for the formation of secondary toxic emissions.

- The cycle must be long enough to collect an adequate sample for trace analysis.

This test procedure was introduced during the implementation of trap technology for off-road machines. The pertinent certification cycle ISO 8178 C1 was adopted.

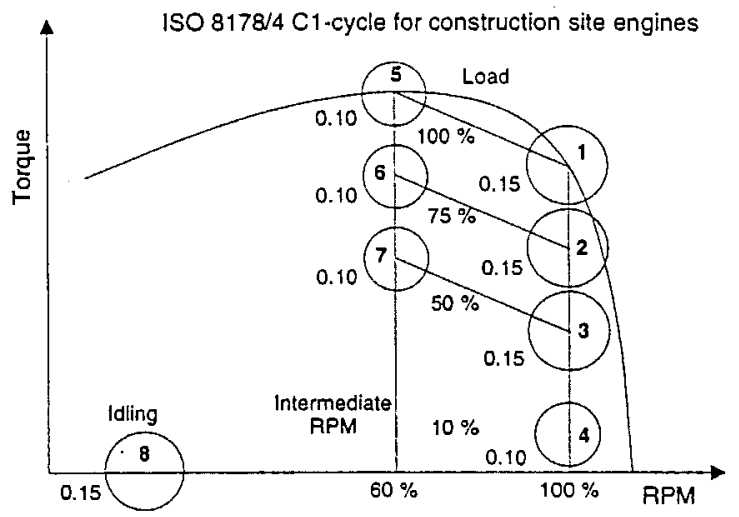

Fig. 1: Test cycle for VSET as per ISO $8178 / 4 \mathrm{C} 1$

The cycle is normally driven in the sequence shown. The holding times per operating points correspond to the weighting factor in minutes. The entire duration of the cycle is thus 100 minutes, which includes the transition from one operating point to the next. The cycle is driven two to four times in sequence to provide a sufficient sampling period. Thus the sampling is during a total cycle time of 200 to 400 minutes. All characteristic conditions for the formation and emission of toxic substances are simulated during the test [6]. Consequently, these pollutants are a realistic proportion of the integral result. 
Figure 2 is an example of the exhaust gas temperature distribution before and after the trap.

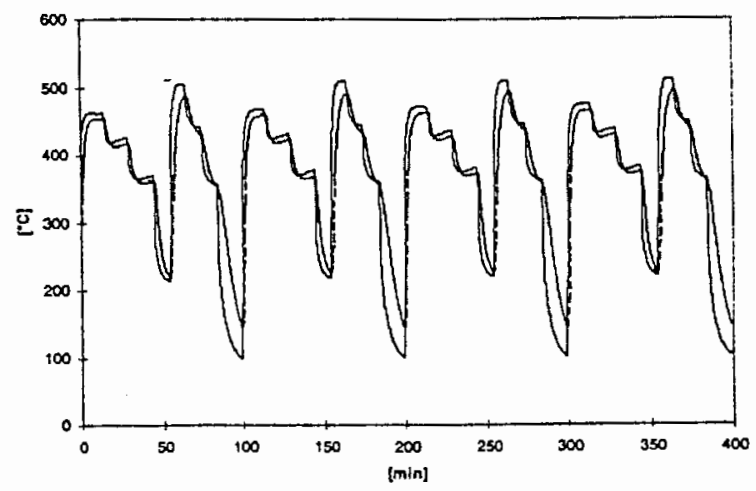

Fig. 2: Temperature profiles before (solid line) and after trap (dotted line) during four ISO 8178/4 C1 cycles

The described test cycle traverses the entire temperature range from idling temperature to full load (including the so-called de-novo synthesis temperature window for the formation of dioxins and furanes and is held sufficiently long at each point.

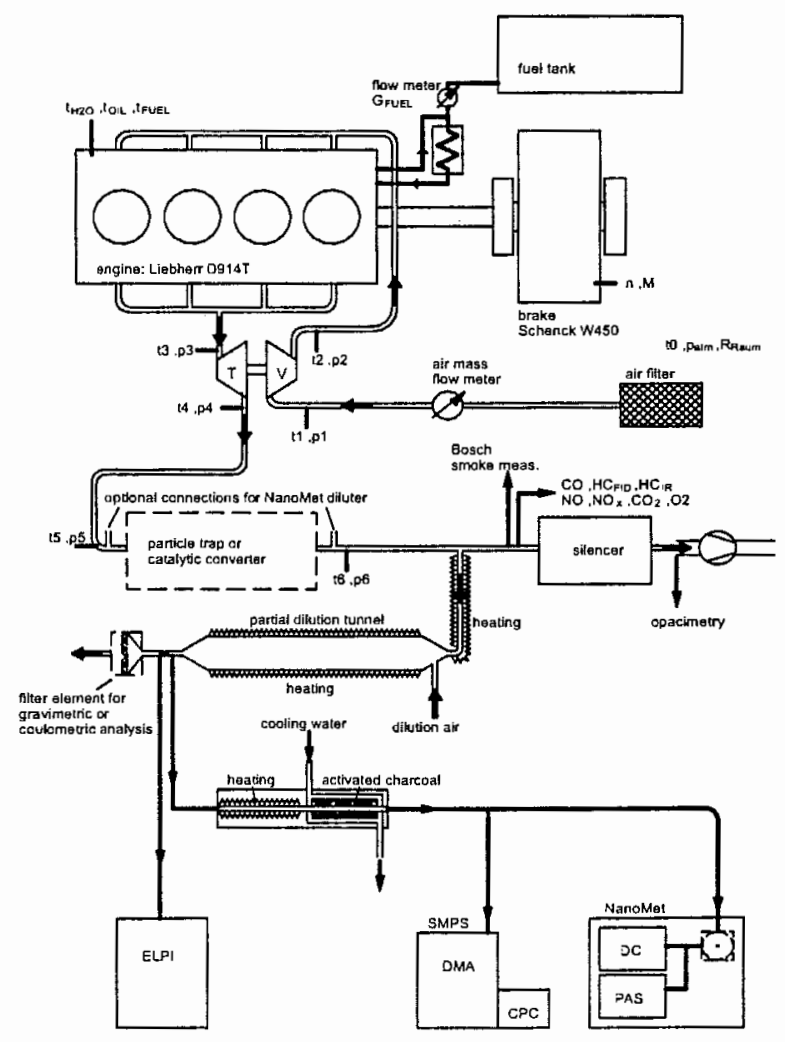

Fig. 3: Schematic of test setup for VERT suitability test for particle trap systems

\section{TEST SETUP}

Test engine

Manufacturer: LIEBHERR

Type:

$914 \mathrm{~T}$

Stroke volume: $\quad 6.11$ liter

Rated power: $\quad 105 \mathrm{~kW}$ at 2'000 RPM

Turbocharger without charge-air cooling

Fuel

Diesel fuel as per EN SN 590

Sulfur content: $\quad<50 \mathrm{ppm}$

Polyaromatics: $\quad 3.5 \mathrm{ppm}$

Density: $\quad 0.832$

Cetane number: $\quad 56.6$

Lubricant

DEA DES $/ 6069$

Sulfur content:

TBN:

$5 \mathrm{ppm}$

$0.55 \mathrm{mg} \mathrm{KOH} / \mathrm{g}$

\section{SAMPLE EXTRACTION}

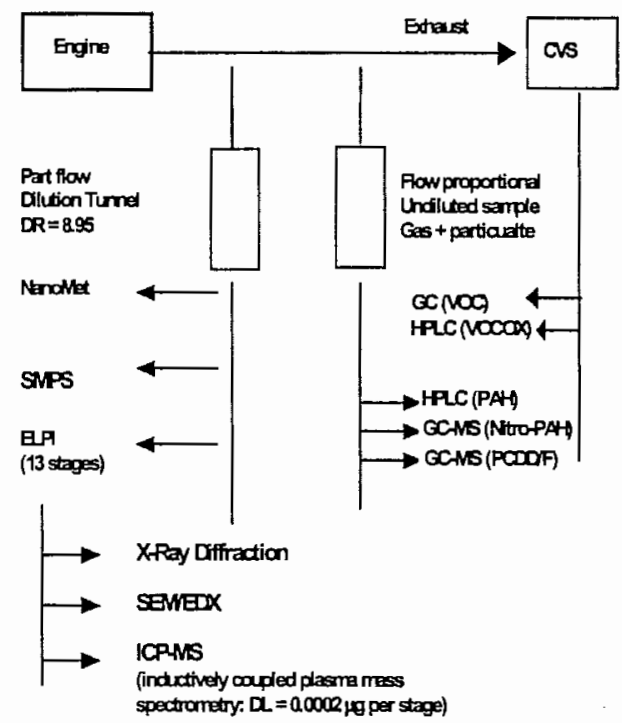

Fig. 4: Schematic arrangement of sample extraction during the secondary emissions tests.

Standard PM-filter arrangement downstream of partflow dilution tunnel is not shown here

Fig 4 shows the schematic for sample extraction and measurement - in this case for the raw gas without trap. Three different sample extraction paths were applied:

- From the undiluted exhaust gas, a flow proportional controlied sample is taken for analysis of the low-volatile compounds (PAH, Nitro-PAH and $\mathrm{PCDD} / \mathrm{F}$ ). Depending on the exhaust gas 
temperature, these are either particle-bound or gaseous. The undiluted extraction facilitates obtaining sufficient quantity of toxic substances within the given time. Even for toxic substances that are only expected in trace quantities, e.g. $\mathrm{PCDD} / \mathrm{F}$, this method provides sufficient accuracy. Sampling is done in a validated collection apparatus made of glass. The apparatus consist of a glass probe, quartz fiber filter, water cooler, condensate collector and a two-stage adsorption unit. Typically $6-9 \mathrm{Nm}^{3}$ undiluted or $30-40 \mathrm{Nm}^{3}$ diluted gas is collected.

- To determine gaseous components, representative exhaust gas aliquots from the dilution tunnel (CVS-System) are collected in Tedlar bags and analyzed as usual.

- From the partial flow dilution tunnel (AVL Smart Sampler), samples are taken for the particle analysis. The dilution is not unfavorable because a high dilution is necessary to prevent condensate artifacts. The measurement procedure has a very high sensitivity.

\section{ANALYSIS}

- The quantitative PCDD/F analysis is based on the known content of ${ }^{13} \mathrm{C}$-labeled PCDD/F standard compounds. After a liquid chromatographic cleaning (LC), the 17 toxically relevant PCDD/F isomers are separated using gas chromatography and detected with a high resolution mass spectrometer (GC-HRMS).

- Certain nitro-PAH, too, can be analyzed with GCHRMS after liquid chromatographic cleaning.

- The PAH analysis is based on a LC method coupled with fluorescence detection.

- The gaseous hydrocarbon content (VOC) of the exhaust gas is analyzed with flame ionization detection, after gas chromatographic separation.

- The partially oxidized exhaust gas components (VOCOX), particularly the carcinogenic formaldehyde and acetaldehyde, are after chemisorbtion determined as pertinent di-nitrophenol-hydrazone using LC-UV

Switzerland has since 1997 a uniform test procedure for verifying suitability of particle trap systems. These tests were developed in collaboration with the manufacturers of traps, catalytic converters and fuelborne catalysts as well as the clean air authorities of the neighbor countries Germany and Austria.

The following sections discuss four important aspects.:

- De novo synthesis of Dioxins and Furans

- PAH-nitration

- Sulfation and

- Shift of nitrogen oxide equilibrium due to catalytic activity within the filter system

\section{COMPARING CATALYSTS FOR DE NOVO SYNTHESIS OF DIOXINS AND FURANS}

Trap system:

- Metal sintered filter/ SHW

Fuel-borne catalysts:

- satacen / OCTEL former PLUTO

Catalyst: $37 \mathrm{mg}$ iron per $\mathrm{kg}$ fuel

- EOLYS DPX 9 / RHONE POULENC

Catalyst: $64 \mathrm{mg}$ cerium per $\mathrm{kg}$ fuel

- OS 96401 / LUBRIZOL

Catalyst: $55 \mathrm{mg}$ copper per $\mathrm{kg}$ fuel

These catalyst treat rates exceed manufacturers typical recommendations by a factor of 2 , which was done on purpose as a worst case scenario.

Fuel:

Reference fuel: CEC RF-03-A-64
Density: $831.5 \mathrm{~kg} / \mathrm{m}^{3}$
Cetane-Number: 52.3
Sulfur content: $430 \mathrm{ppm}$

The fuel was doped with chlorinated additives to verify sensitivity of the PCDD/F reaction.

- Reference fuel: < $2 \mathrm{mg}$ Chlorine per $\mathrm{kg}$ fuel

- Doping stage 1: $10 \mathrm{mg}$ Chlorine per $\mathrm{kg}$ fuel

- Doping stage 2: $100 \mathrm{mg}$ Chlorine per $\mathrm{kg}$ fuel

Legend for the following diagrams:

RO: Reference without trap

RM: Reference with trap

EO: Iron catalyst without trap

EM: Iron catalyst with trap

CO: Cerium catalyst without trap

$\mathrm{CM}$ : Cerium catalyst with trap

$\mathrm{KO}$ : Copper catalyst without trap

$\mathrm{KM}$ : Copper catalyst with trap

$\mathrm{H}$ : $\quad$ Chlorine additive $10 \mathrm{mg} / \mathrm{kg}$ fuel

$\mathrm{X}$ : Chlorine additive $100 \mathrm{mg} / \mathrm{kg}$ fuel

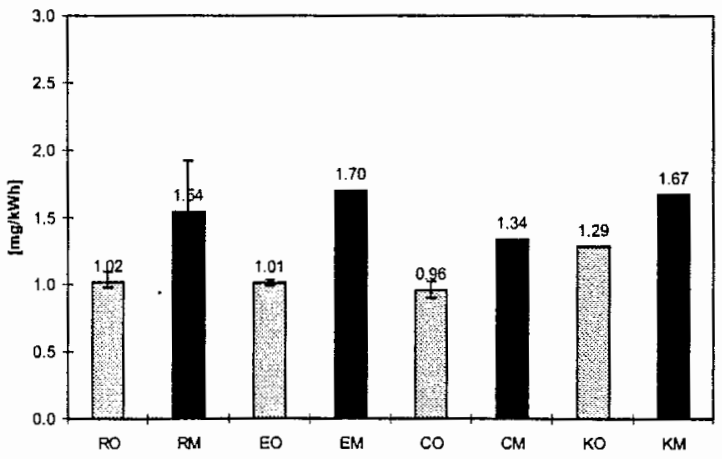

Fig. 5: Mean benzene emissions 


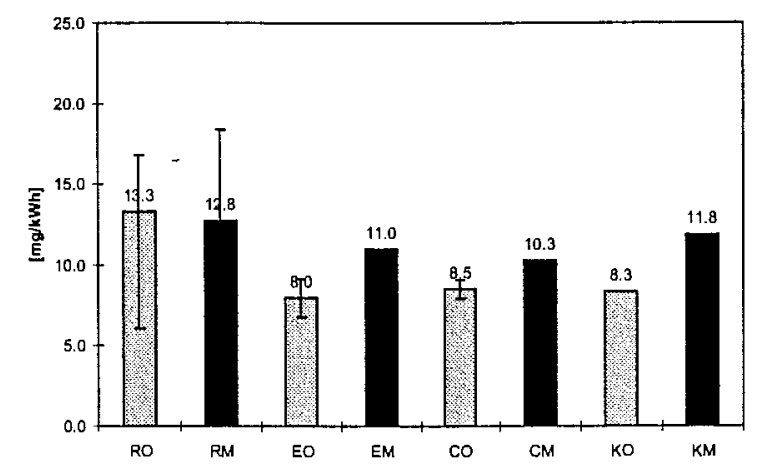

Fig 6: Mean formaldehyde emissions.

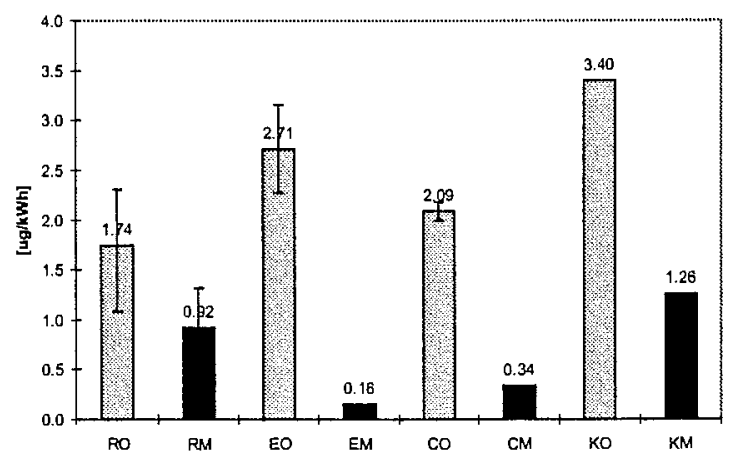

Fig 7: Mean emission factors for the sum of all carcinogenic $\mathrm{PAH}$, as per EPA.

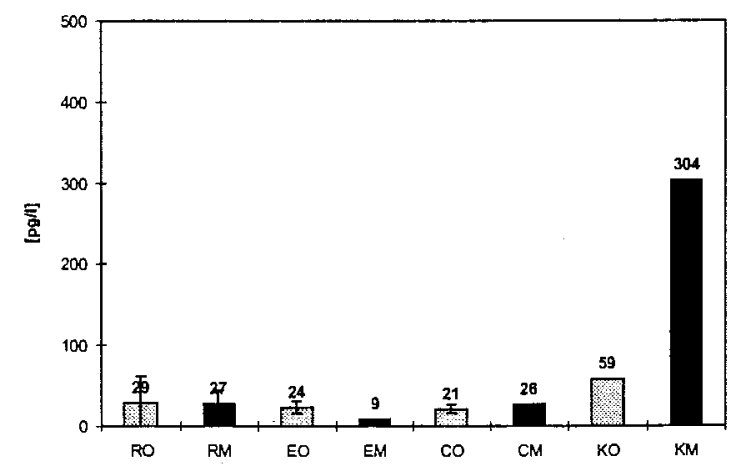

Fig.8: Mean emission factors for the poly-chlorinated dioxins and furans (TEQ sum)

(Reference is without Chlorine additive)

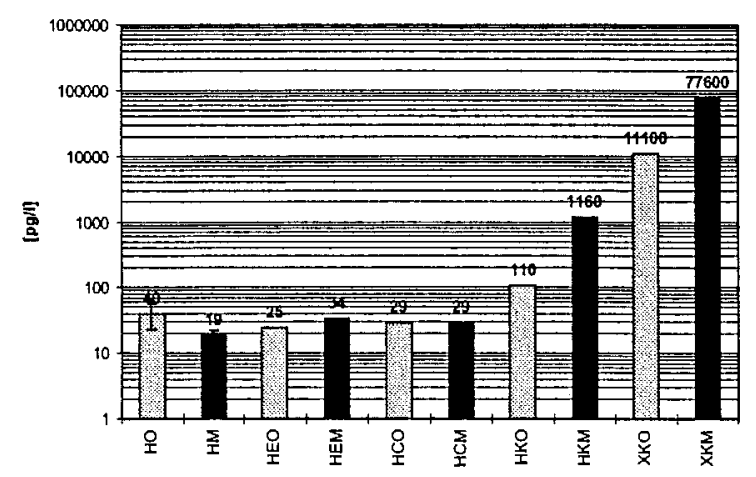

Fig. 9: Mean emission factors for polychlorinated dioxins and furans (TEQ sum) for fuel with supplementary Chlorine.

The results are an extract from the comprehensive investigations $[7,8]$, comprising the shown variants and other trap systems. The main findings are:

- Particle traps apparently slightly increase the benzene emissions, which is at a very low level typical of diesel engines. Benzene and other low molecular hydrocarbons are formed during most incomplete combustion processes. Hence, some benzene formation will occur during the decomposition of diesel soot.

- There is no significant change in the emission of formaldehyde.

- Traps strikingly diminish carcinogenic polycyclic aromatic hydrocarbons (PAH). The deployment of fuel-borne catalysts significantly strengthens this effect and curtailment to $10 \%$ of the initial value was observed. The explanation for this phenomenon is the deposition of PAH on the particles [2]. Subsequently, these are trapped in the filter and during regeneration converted together with the soot.

- Trap technology does not itself synthesize polychlorinated dioxins and furans.

- The fuel-borne catalysts iron and cerium do not influence the synthesis of polychlorinated dioxins and furans.

- Copper, however, causes a significant increase in the emissions of polychlorinated dioxins and furans [9]. This effect is amplified to dangerous orders of magnitude when even a small quantity of chlorine is present, which often occurs in realistic deployment conditions. Supplementary 100 ppm chlorine can result in 3 orders of magnitude increase in polychlorinated dioxins and furans. Consequently, Swiss authorities prohibited the frequently used fuel-borne copper catalyst. 


\section{INVESTIGATION OF PAH NITRATION IN PARTICLE TRAP SYSTEMS}

Trap induced nitration of PAH can cause increased emissions of nitro-PAH, feared for its genotoxic potential $[10,11,12]$. The VERT suitability tests addressed this suspicion. A comprehensive investigation was done for the following variants.

\begin{tabular}{|l|l|l|l|}
\hline & Catalyst & Fuel & Filter \\
\hline 01 & - & Standard & - \\
\hline 02 & $\mathrm{Ce} / \mathrm{Pt}$ & Standard & - \\
\hline 03 & $\mathrm{Ce} / \mathrm{Pt}$ & Standard & Fiber knit 1 \\
\hline 04 & $\mathrm{Ce} / \mathrm{Pt}$ & $+\mathrm{Cl} 10 \mathrm{ppm}$ & Fiber knit 1 \\
\hline 05 & $\mathrm{Ce} / \mathrm{Pt}$ & $+\mathrm{Cl} 10 \mathrm{ppm}$ & - \\
\hline 06 & - & Standard & - \\
\hline 07 & $\mathrm{Fe} / \mathrm{Sr}$ & Standard & - \\
\hline 08 & $\mathrm{Fe} / \mathrm{Sr}$ & Standard & SiC Wall-Flow 1 \\
\hline 09 & $\mathrm{Fe} / \mathrm{Sr}$ & $+\mathrm{Cl} 10 \mathrm{ppm}$ & SiC Wall-Flow 1 \\
\hline 10 & $\mathrm{Fe} / \mathrm{Sr}$ & $+\mathrm{Cl} 10 \mathrm{ppm}$ & - \\
\hline 11 & $\mathrm{Fe} / \mathrm{Sr}$ & $+\mathrm{Cl} 10 \mathrm{ppm}$ & $\mathrm{SiC}$ Wall-Flow 1 \\
\hline 12 & $\mathrm{Fe} / \mathrm{Sr}$ & $+\mathrm{Cl} 10 \mathrm{ppm}$ & $\mathrm{SiC}$ Wall-Flow 1 \\
\hline 13 & & & \\
\hline 14 & $\mathrm{Fe} / \mathrm{Sr}$ & $+\mathrm{Cl} 100 \mathrm{ppm}$ & SiC Wail-Flow 1 \\
\hline 15 & - & $+\mathrm{Cl} 10 \mathrm{ppm}$ & SiC Wall-Flow 2 \\
\hline 16 & $\mathrm{Ce}$ & $+\mathrm{Cl} 10 \mathrm{ppm}$ & SiC Wall-Flow 2 \\
\hline 17 & $\mathrm{Fe}$ & Standard & SiC Wall-Flow 2 \\
\hline 18 & $\mathrm{Ce} / \mathrm{Pt}$ & Standard & Fiber knit 2 \\
\hline 19 & - & Standard & CRT \\
\hline $\mathrm{Tab}$ & & \\
\hline
\end{tabular}

Table 1: Particulate trap technology parameters investigated during the Nitro-PAH-study [13]
Correct sampling is crucial in nitro-PAH analysis. Quantitative changes (increase or decrease) can occur during sample extraction and preparation. To verify artifact formation, ${ }^{13} \mathrm{C}$-labeled substances were added to the sample before the tests and subsequently sought.

Indeed, during sampling, up to $50 \%$ of ${ }^{13} \mathrm{C}$-labeled pyrene was converted into the corresponding nitropyrene. The nitration of other PAH, e.g. naphthalene and phenanthrene during sampling is, however much less efficient. The observed increase in nitronaphthalene and nitro-phenanthrene emissions from particle traps is hence not due to sampling artifacts.

The following figures show some typical results. The pertinent legend is:

$\begin{array}{ll}\text { R: } & \text { Reference diesel } \\ \text { H: } & \text { Reference diesel with } 10 \mathrm{ppm} \text { chlorine } \\ \mathrm{X}: & \text { Reference diesel with } 100 \mathrm{ppm} \text { chlorine } \\ \mathrm{P}: & \text { Cerium/Platinum } \\ \mathrm{S}: & \text { Iron/Strontium } \\ \mathrm{C}: & \text { Cerium } \\ \mathrm{E}: & \text { Iron } \\ \mathrm{O}: & \text { Without trap } \\ \mathrm{F}: & \text { With trap } \\ \mathrm{B}: & \text { SiC Wall-Flow } \\ \mathrm{CRT}: & \text { Continuously Regenerating Trap }\end{array}$

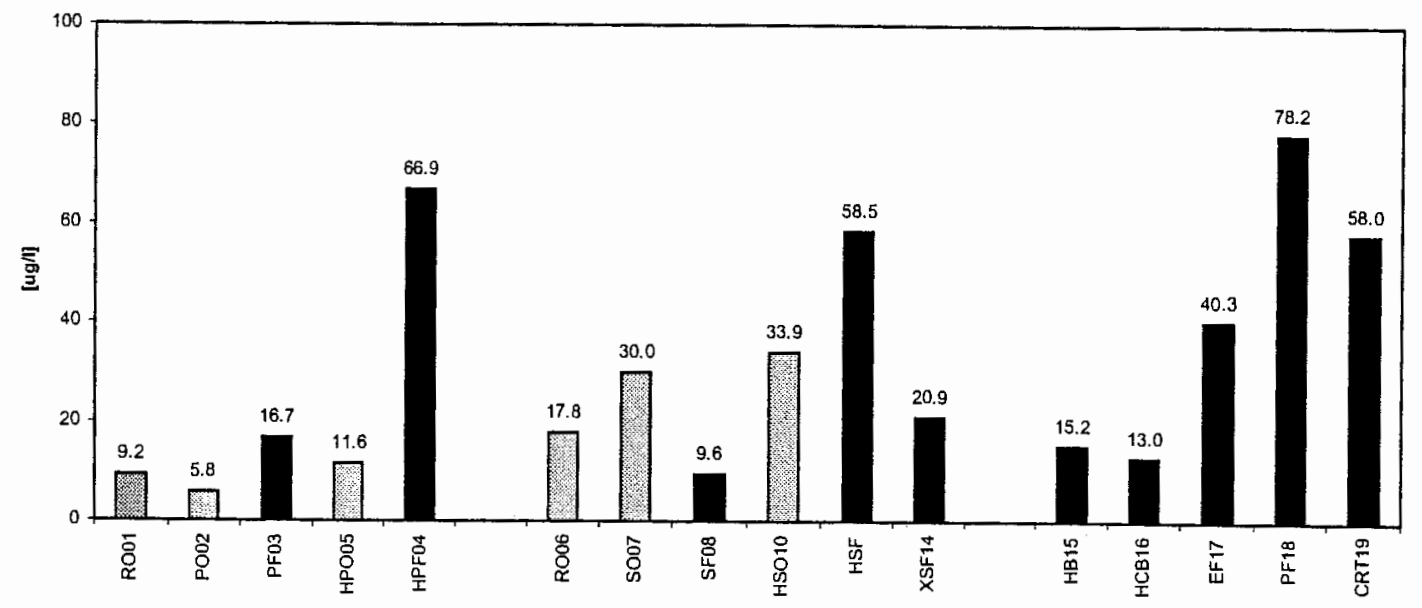

Fig. 10: Emission factors for the sum of 2-4-ring nitro-PAH in $\mu \mathrm{g} / /$ fuel 


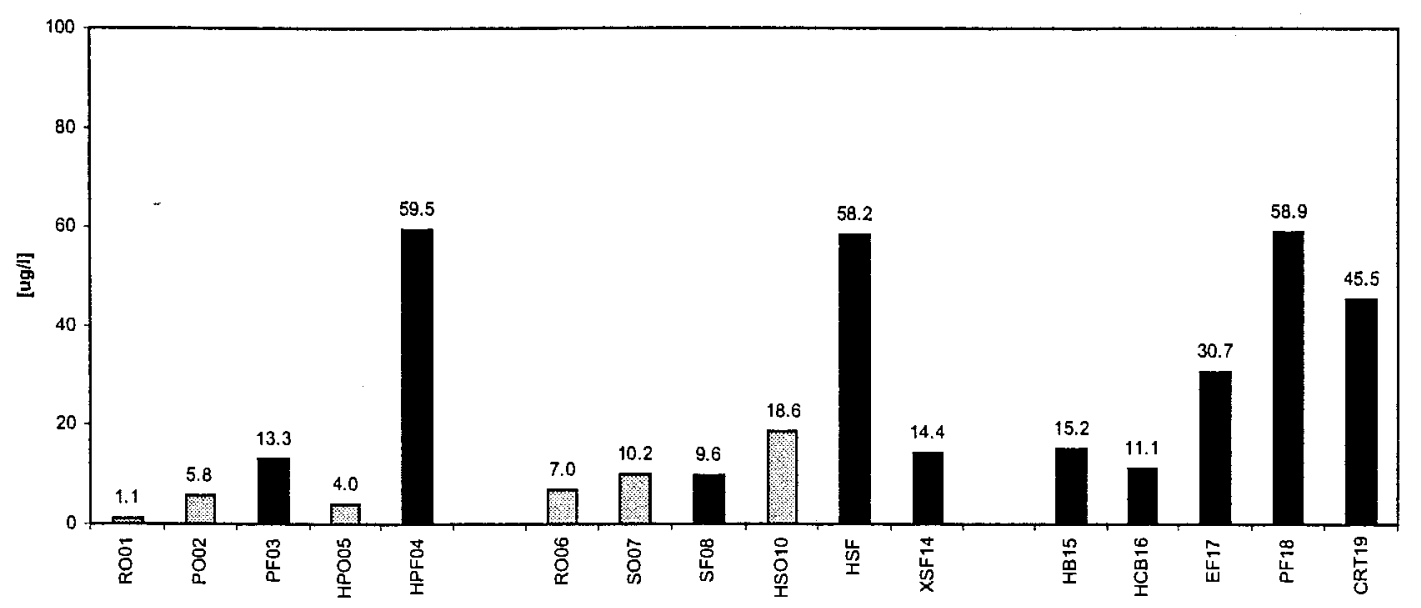

Fig.11: Emission factors for 2-ring nitro-PAH in $\mu \mathrm{g} / \mathrm{l}$ fuel

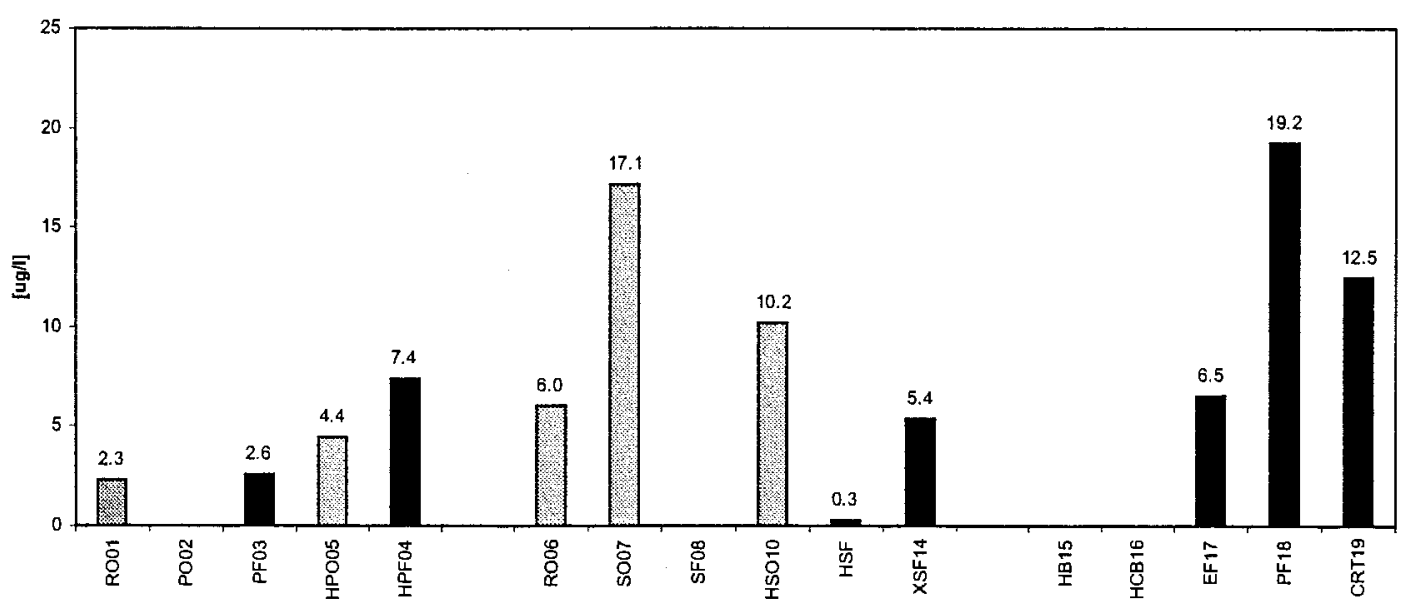

Fig. 12: Emission factors for 3-ring nitro-PAH in $\mu \mathrm{g} / \mathrm{l}$ fuel

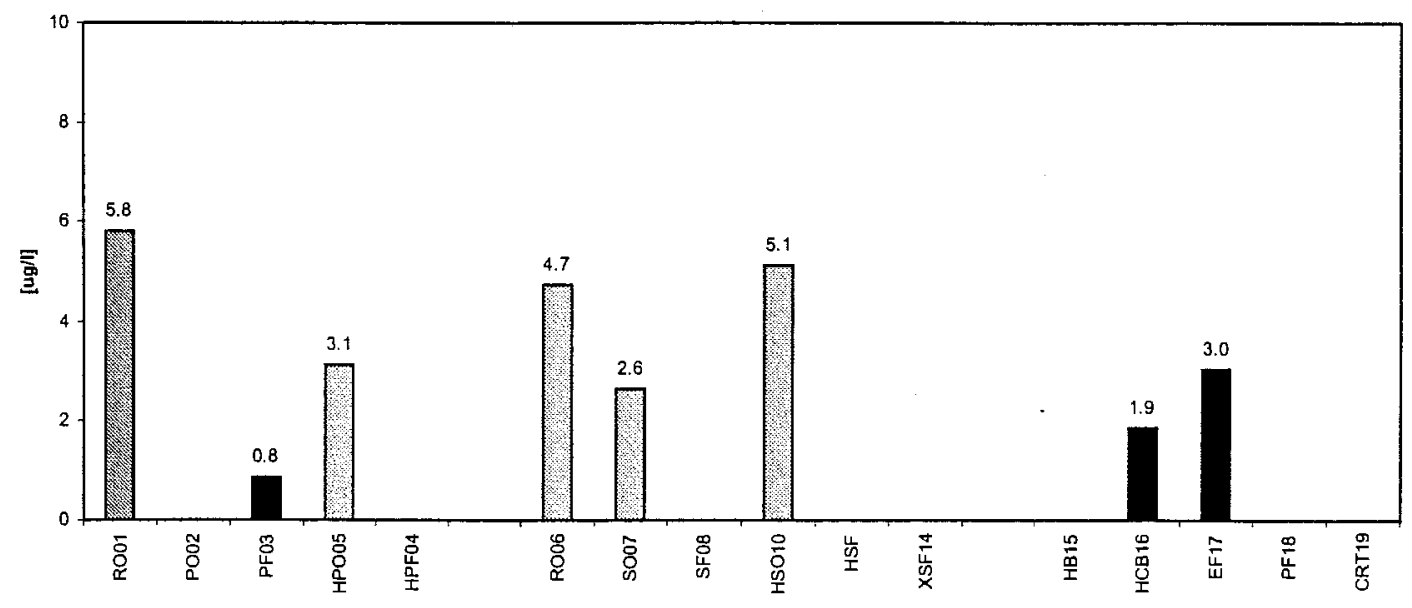

Fig. 13: Emission factors for 4-ring nitro-PAH in $\mu \mathrm{g} / \mathrm{l}$ fuel 
The following observations are obtained from comparative evaluation of the nitro-PAH data:

- The emission levels of nitro-PAH is lower than the $\mathrm{PAH}$, i.e. only a few $\mu \mathrm{g}$ per liter fuel. This is close to the detection limits of the analytical procedure employed. Hence, it is difficult to differentiate effects for specific trap technologies.

- The sum of detectable nitrated PAH is mainly due to the volatile 2-ring nitro-PAH. The less volatile 3 ring and 4-ring nitro-PAH are a much smaller proportion.

- 2-ring nitro-PAH are synthesized in the investigated trap systems and re-emitted due to its volatility.

- Detected 3-ring nitro-PAH are mainly nitrated phenanthrene and anthracene. levels of nitro-PAH are lower than those of $\mathrm{PAH}$.

- The most prominent 4-ring nitro-PAH is 1-nitropyrene. It is mainiy found in unfiltered raw gas. Sometimes relevant sampling artifacts occur, i.e. a significant proportion of detected 1-nitro-pyrene was formed during sampling.

- Thus nitro-PAH are synthesized in the trap system but with decreasing volatility are also retained or decomposed in the trap system.

- In contrast, the volatile nitro-PAH partially synthesized in the trap, exit it and there is a tendency for higher emissions.

The prevailing conditions are the low concentrations, the high scatter and artifact formation of such substances during sampling.

Hence, it cannot be established that the investigated trap-technology variants are responsible for relevant secondary emissions of the nitro-PAH group. The toxically relevant nitro-PAH are low-volatile and hence are most probably retained in the particle trap, unlike the volatile 2-ring nitro-PAH.

\section{THE CATALYTIC EFFECT OF PRECIOUS METALS IN CRT-SYSTEMS}
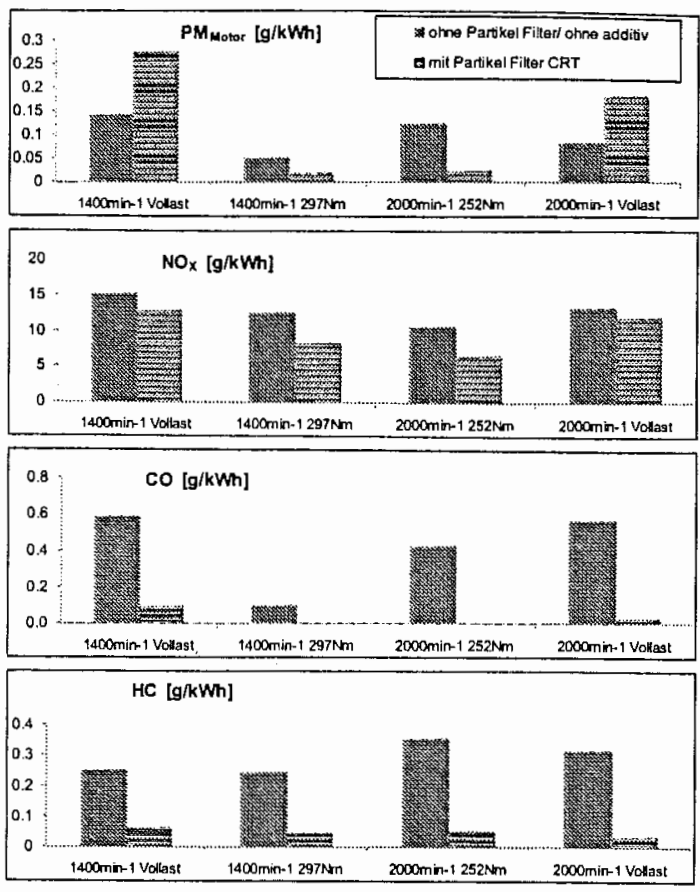

Fig. 14: CRT system emission of limited emissions using legislated sampling and measuring techniques ie cold sampling of Nox

CRT = Continuous Regenerating Trap is the acronym for a Johnson Matthey patented particle trap system. It consists of a platinum-coated substrate upstream of the uncoated filter. Suitability tests measurements were performed on such a system [14] in the VFT3 tests, i.e. after field deployment (2'458 hours during more than 2 years). Some typical effects are described below. Note, however, that precious metals are also used in mixed filter coatings and as fuel-borne catalysts. The same effects were not observed in all situations [15], neither favorable nor unfavorable.

Figure 14 shows a preliminary overview of the classical emission components $\mathrm{HC}, \mathrm{CO}, \mathrm{NOx}$ and $\mathrm{PM}$ according to conventional (legally mandatory) metrology.

The very efficient curtailment of $\mathrm{CO}$ and $\mathrm{HC}$ was confirmed in all operating points as expected. Surprising were the results for the two other pollutant components:

- $\mathrm{NO}_{x}=\mathrm{NO}+\mathrm{NO}_{2}$ is massively diminished at most operating points. That would be a very welcome result and was observed with many CRT systems. Actually, a discrepancy results from the strong conversion $\mathrm{NO} \rightarrow \mathrm{NO}_{2}$, as shown later. The mandatory measurements are done on a cold sample. The very hygroscopic $\mathrm{NO}_{2}$ is in the 
condensate and disappears from the observation. This is a serious and widely occurring artifact.

- The particle mass PM, too, was measured according to the prescribed test method. At many operating points, there was some but minor curtailment. At the two full load points, PM increase was observed, i.e. substantially more particle mass was found after the trap than before the trap indicating a trap induced PM - formation. The summary results indicate several secondary emission problems of the system. These are the strong sulfating $\mathrm{SO}_{2} \rightarrow \mathrm{SO}_{3}$ and the shift in nitrogen oxide equilibrium from $\mathrm{NO} \rightarrow \mathrm{NO}_{2}$.

\section{Sulfating:}

The tests were done with a Swiss standard fuel EN-SN 590 having a sulfur content of $50 \mathrm{mg} / \mathrm{kg}$ This is the prescribed fuel quality for Switzerland effective January 2005. The effect of sulfating is illustrated for filtration rates of traps measured using different methods.

\begin{tabular}{|l|c|c|c|c|l|}
\hline & $\begin{array}{l}2^{\prime} 000 \\
\text { RPM } \\
\text { full load }\end{array}$ & $\begin{array}{l}1^{\prime} 400 \\
\text { RPM } \\
\text { full load }\end{array}$ & $\begin{array}{l}2^{\prime} 000 \\
\text { RPM } \\
\text { half load }\end{array}$ & $\begin{array}{l}1^{\prime} 400 \\
\text { RPM } \\
\text { half load }\end{array}$ & $\begin{array}{l}\text { Avera } \\
\text { ge }\end{array}$ \\
\hline PMAG & -118.4 & 29.7 & 81.4 & 62.3 & 13.7 \\
\hline $\begin{array}{l}\text { PZAG } \\
\text { 20-200 }\end{array}$ & 21.9 & 76.1 & 100.0 & 98.4 & 36.1 \\
\hline $\begin{array}{l}\text { PZAG } \\
\text { 50-200 }\end{array}$ & 99.8 & 95.3 & 99.9 & 99.8 & 98.7 \\
\hline ECAG & & 98.5 & & & 98.5 \\
\hline PASAG & 99.9 & 99.9 & 99.9 & 99.8 & 99.9 \\
\hline DCAG & 98.5 & 99.5 & 96.0 & 97.2 & 97.8 \\
\hline
\end{tabular}

Table 2: CRT (Continuos Regeneration Trap) filtration rate measured using 6 different methods

PMAG: Gravimetric as legislated.

PZAG: Particle count (SMPS + CNC) integrated from 20-200 nm and 50-200 nm respectively.

ECAG: Coulometric of elementary carbon mass.

PASAG: PAS (surface area of all combustion particles, PAS = photoelectric aerosol sensor of the NanoMet technology).

DCAG: DC measurement (surface area of all particles, $D C=$ diffusion sensor of the NanoMet measurement technology).

The comparison delivers a clear picture:

- Measurement methods that only detect solid particles, e.g. Coulometry, PAS and DC, indicate the trap filtration rate exceeds $98.5 \%$. After 2 '500 operating hours, this is exceptionally good.

- The particle count integration of the SMPS, excluding the so-called nucleation particles, i.e. condensate occurring after the trap, has the same response.

- The filter evaluation is severely distorted, when condensates are included, i.e. integrated in the range $20-50 \mathrm{~nm}$.
- Total PM measurement apparently is inappropriate in the context of filter efficiency testing: PM includes the very strong sulfating and hence formation of sulfuric acid droplets. These are deposited in the measurement filter and additionally bind much water. These are completely irrelevant to the filtration efficiency, because it only captures particles that under through-flow conditions are solids. The PM metric therefore is entirely irrelevant to the physics of a Diesel particle filter.

Figure 15 convincingly illustrates this condensation phenomenon, at full load conditions. Data is from SMPS particle size distribution.

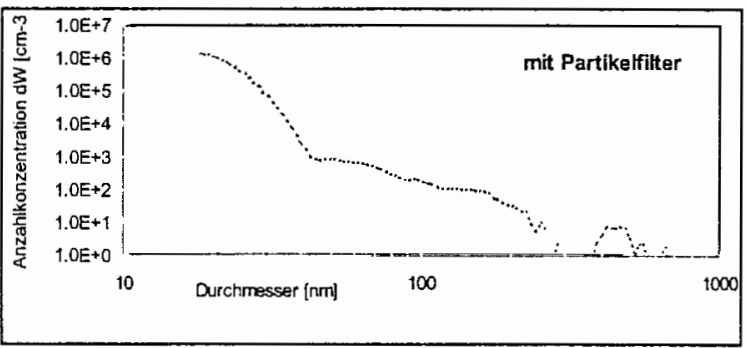

Fig.15: Particle-count per $\mathrm{cm}^{3}$ as function of particle mobility size [nm] downstream of a particle filter, at 2000 RPM and full load.

Formation of $\mathrm{NO}_{2}$

The formation of $\mathrm{NO}_{2}$ from $\mathrm{NO}$ in the oxidation catalytic converter is the principle of the CRT system. It explains the very low regeneration temperatures of this method, due to the release of oxygen radicals from decomposition of the unstable $\mathrm{NO}_{2}$, at these temperatures in the filter structure. To ensure trap regeneration at all operating conditions, an $\mathrm{NO}_{2}$ surplus must prevail and therefore $\mathrm{NO}_{2}$ penetration is inevitable.

The respiratory toxicity of $\mathrm{NO}_{2}$ is $6-10$ times that of NO. Thus, secondary emissions at workplaces, i.e. in the proximity of machines, are critical [16]. Moreover, $\mathrm{NO}_{2}$ is an ozone precursor. Hence, there are two good reasons for careful scrutiny of this emission component.

To correctly measure $\mathrm{NO}_{2}$, sampling must be done at high temperatures to prevent condensation of the combustion vapors. The gases must be free from water vapor using a membrane dehumidifier before admission into the nitrogen oxide analyzer. The results are shown in Figure 16 

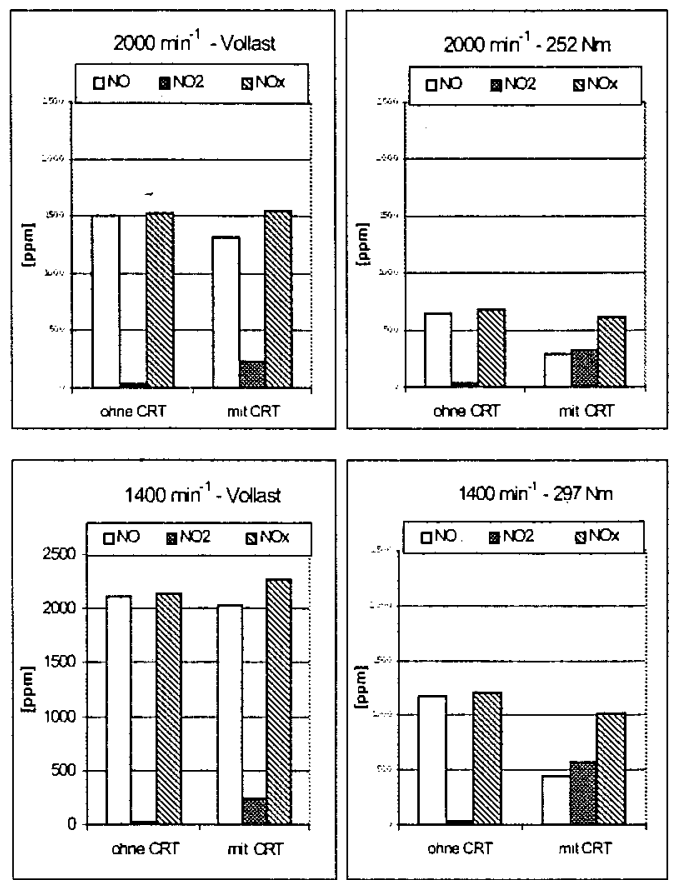

Fig. 16: $\mathrm{NOx} / \mathrm{NO} / \mathrm{NO}_{2}$ measurements with (mit) and without (ohne) CRT. Hot sampling with membrane dehumidification.

Correct sampling leads to the following observations:

- The apparent curtailment of nitrogen oxide NOx (which should better be called $\mathrm{NO}+\mathrm{NO}_{2}$ ) (Figure 14) in a CRT system is clearly an artifact. Accurate measurements using heated sampling lines show that the total oxides of nitrogen are practically unchanged when the CRT trap is deployed.

- The CRT system diminishes NO concentration.

- The $\mathrm{NO}_{2}$ concentration rapidly increases when the CRT system is deployed, particularly at part load. As temperature increases, first the CRT increases the rate at which $\mathrm{NO}$ and $\mathrm{NO} 2$ reach thermodynamic equilibrium, increasing the proportion of the latter. At higher temperatures, dissociation shifts the equilibrium in favor of NO. This phenomenon defines the so-called CRT temperature aperture.

The measured $\mathrm{NO}_{2}$ concentrations of up to $500 \mathrm{ppm}$ are very high indeed compared to workplace limits of $3 \mathrm{ppm}$ in Switzerland or $1 \mathrm{ppm}$ in Sweden, despite the assumption of a workplace dilution factor of about 40 .

\section{CONCLUSIONS}

The results unfortunately confirm the hypothesis that catalytic active particle traps can show both beneficial and undesirable reactions. Examples of the latter were found during the reported investigations, within the scope of the VERT suitability tests.

The evolution in the test procedures has matured into the VSET (VERT Secondary Emissions Test). It now covers about 200 toxic substances and is an important part of the suitability test suite. Further developments are anticipated.

Systematic testing of all catalytic active systems resulted in specific technical recommendations, e.g. prohibition of copper as fuel-borne catalyst. Systems with precious metal coatings have unfavorable attributes that could restrict their deployment.

The majority of tested trap systems exhibit desirable characteristics, even in these very meticulous analyses of secondary emissions in the trace quantity range. Such traps are approved in the Swiss list of certified traps for unrestricted deployment.

\section{ABBREVIATIONS}

$\mathrm{DC}$

ECAG

EPA Environment Protection Agency

PAS Photoelectric Sensor of NanoMet-

Metrology

PCDD/F Polychlorinated Dibenzo-Dioxins and Furanes

PMAG Filtration efficiency based on

particulate matter PM

TEQ Toxicity-Equivalent

VERT Verminderung der Emissionen von

Real-Dieselmotoren im Tunnelbau International project to reduce Diesel emissions in tunneling 1994-2000

VFT VERT Filter-Suitability Test

VSET VERT Secondary Emissions Test 


\section{REFERENCES}

1. Mayer et al., Particulate Traps for Retrofitting Construction Site Engines. SAE 1999-01-0116

2. M.Kasper, Ferrocene, Carbon Particles and PAH in a Methane Diffusion Flame. Dissertation ETH $12725 / 1998$

3. Tested and Approved Particle-Trap Systems for retrofitting Diesel engines, VERT Filter List, $17^{\text {th }}$ July 2002 http://www.umwelt-schweiz.ch/buwal

4. Directive of the Swiss Federal Justice and Police Department of 7 August 1990

5. A.Mayer et al., Penetration of metallic additive particles through Diesel particle traps. SAE-Paper 2003-01 Proposal 03FL-162

6. I. Fängmark et al., Influence of post combustion temperature profiles on the formation of PCDDs, PCDFs, PCBzs and PCBs in a pilot incinerator, Environmental Science \& Technology 28 (1994), 624-629

7. N.V.Heeb, EMPA-Report 167985, Influence of particulate trap systems on the composition of exhaust-gas emissions. Part 1, 1998, 1-70. Dübendorf

8. NV.Heeb, EMPA-Report 172847, Influence of particulate trap systems on the composition of Diesel engine exhaust gas emissions, Part 2. 1998, 1-70, Dübendorf
9. C. Clunies-Ross et al., Dioxins in diesel exhaust, Nature 381 (1996) 379

10. 3-Nitrobenzanthone, a powerful bacterial mutagen and suspected human carcinogen found in Diesel exhaust and airborne particles. Takeji Enya et al, Environmental Science \&Technology / Vol. 31,10, 1997

11. I.Zwirner-Baier, HG Neumann, Nitro-PAH's as biomarkers of exposure to Diesel exhaust. Mutat Res. 1999, 441:135-144

12. G.Remberg, Zur Bestimmung von polyzyklischen aromatischen Kohlenwasserstoffen und ihren Nitroderivaten in Dieselruss mittels Chromatographie und hochauflösender Massenspektrometrie. Dissertation Vienna, Nov.1998

13. N.V.Heeb, EMPA-Report 418527 (AKPF-study), Influence of particulate trap technology on the emissions of nitrated polycyclic aromatic hydrocarbons, 2000, 1-37, Dübendorf

14. J.Czerwinski et al, VERT-Filter Test, Phase 3 mit dem HJS-CRT-System am Liebherr D914T Baumaschinenmotor ; B097 / 2001 Abgasprüfstelle Nidau

15. MSHA Program Information Bulletin Www.msha.gov

16. Thresholds of toxic air contaminants 2001 according to Swiss occupational health authority SUVA. 